\title{
Sleep apnoea and telemonitoring
}

\section{The patient and healthcare professional perspective}

\section{Patient perspective}

David Hirst, who was diagnosed with sleep apnoea 18 years ago

I started experiencing symptoms of extreme tiredness and severe lethargy about 18 years ago, a short while after an angina attack. I thought the symptoms were related to my angina and I did not immediately seek help.

I was working in a high-powered job, overseeing a large factory and there was a lot of stress, which, under normal circumstances, I loved. However, feeling so extremely tired all the time I was unable to function properly at work. Not even unwinding on weekends away seemed to make a difference; on Monday morning I was just as exhausted as I had been on the Friday when I finished work.

During an appointment with my endocrinologist, I mentioned I had recently fallen asleep whilst driving and my consultant took me to a different department immediately, where I was told I had sleep apnoea. This was confirmed a few days later in the sleep clinic and I was given a continuous positive airway pressure (CPAP) machine within a very short period of time.

Temporarily, I was worried about the effect the diagnosis would have on my work, as I was not allowed to drive. However, getting the CPAP machine changed my life. Within 48 hours, I felt not only better, but like my old self again, being able to enjoy my life, my work and all the stress that comes with my job. I received lifestyle advice from the healthcare professionals in the sleep clinic and, as a result, I changed my sleeping environment, when and what I ate, as well as my alcohol intake and I have not had any symptoms of sleep apnoea for many years now.

When my hospital in Stranraer was looking to introduce telemedicine to some departments about 3 years ago I was asked whether I wanted to be part of the trial. I have several other chronic conditions and need to see an endocrinologist and a renal consultant regularly, as well as attend the sleep clinic for check-ups. I am a regular outpatient at the hospital and so I grabbed the opportunity of trialling telemedicine with both hands.

I haven't really looked back since then. Telemedicine was easy for me to get on with, as I had been using computers as part of my job for many years. I felt there wasn't anything to be scared of. There was always a nurse with me in case of problems, and it is only like Skyping. I think a lot of older people, who might previously have been scared of technology, could manage telemedicine.

I found it liberating. It freed up a lot of time for me, which I would otherwise have had to spend at the hospital. My nearest hospital is 27 miles away, and my surgery is 17 miles away. This means a lot of travelling time and costs for fuel and parking.

Another very positive result of telemedicine for me is that my consultants seem available more often and are more flexible; it is much easier to get appointments with them. I think telemedicine should be embraced especially in remote areas, where a hospital visit can result in a day or two of travelling and huge costs. I am very positive about the future and my quality of life. 
Phyllis Murphie, Respiratory Nurse Consultant at NHS Dumfries and Galloway in Scotland

In 1997, I became a respiratory nurse specialist at a medical surgical diagnostic unit that covered sleep medicine, among other areas. At this time, we decided to invest in limited polysomnography, and the service has subsequently developed over the last 18 years.

Working in a remote and rural region, I am drawn to video consultations as a way to support people who would otherwise have to travel a $250-$-mile round trip to be seen in a clinic. We started using teleconsultation in sleep medicine about 2 years ago with a small number of people. This year, we evaluated patient satisfaction with the service in a fairly large group and got a more than $60 \%$ response rate on the patient satisfaction survey. We now consider this to be a mainstream service and are exploring other areas of respiratory medicine where we could use this technology.

Teleconsultation can be used in straightforward clinical reviews for people with sleep apnoea because they do not specifically require physical examination of the patient. You are discussing issues such as compliance with treatment, symptoms, side effects of the treatment, mask fit and mask leak. People who have been established on treatment for 1-2 years or who may not be able to travel fit this service perfectly.

Our service is carried out through a big television screen mounted on a trolley with a video conference box attached, which patients access through their local clinic. We are also exploring whether we can securely use this technology on patients' own desktop monitors, via Skype or FaceTime.

David was one of the first people we invited onto the service. We thought it would be ideal for him for a number of reasons. David has always taken his healthcare self-management on board and is keen to engage with new and innovative services. He also lives about a 100-mile roundtrip from the centre and has to attend multiple clinical review appointments for his other health issues. This mode of review helps him to organise his healthcare around his own needs and cut down his travel.

I hope that this can be offered to more patients and in more centres across Scotland in the future. For example, I have been speaking to colleagues who work with patients living on islands whose travel expenses are very high about how this service could work for them.

New telemonitoring options are always becoming available. There are now CPAP machines that store patient-use data that allow for remote monitoring. So, for instance, I could look at a patient's data to see how they were doing with the therapy before speaking to them during the review. I think that this could be very useful for vocational drivers, for example, who could do their review while they were on the road.

We are also looking into enabling people to engage with the service when they need it, and are just about to trial a new self-management plan for sleep apnoea.

I would advise other healthcare professionals interested in offering a telemedicine service like this to do some research into what other local centres are offering. Talk to people delivering these services and see if you can visit to look at how it is being done.

When you set up a telemedicine service, you should reassure users that they will still receive the same level of care as they would get face-to-face. If you already have a relationship with a patient face-to-face, then the transition to telemedicine reviews is easy.

You need to learn slightly different consultation skills and make sure that you can convey the same level of communication as you would face-to-face. Maintaining eye contact is important, so you need to make sure you look up into the camera and avoid keeping your head down to write case notes.

It is also important to remember that this method of review is not suitable for everyone. For example, people with diabetes may need face-to-face reviews because they will need to have blood samples taken. People need to feel comfortable using the service too; it depends on how they would feel in front of a screen.

As well as offering patients the chance to fit their clinical reviews around their own lives, our service has brought other wider benefits, including reduced fuel consumption and carbon emissions associated with travelling to a clinical review. It has also freed up many of my clinical sessions and made me more available for my patients as I'm not spending as many hours travelling around.

I think that it is vital to think about whether you do things a certain way because that is how you have always done them, or whether are you looking at service design and innovation and trying to put people at the centre of their care. 